\title{
SUJEITO E OBJETO FOCALIZADOS NAS SENTENÇAS SVO DO PORTUGUÊS BRASILEIRO
}

\author{
SUBJECT AND OBJEC FOCUZING IN SVO SENTENCES FROM BRAZILIAN PORTUGUESE \\ SUJETO Y OBJETO FOCALIZADOS EN LAS SENTENCIAS SVO DEL PORTUGUÉS BRASILEÑO \\ Sandra Quarezemin* \\ Universidade Federal de Santa Catarina - UFSC, Florianópolis, BR
}

\begin{abstract}
RESUMO: Este trabalho trata da focalização do sujeito e do objeto nas sentenças SVO do português brasileiro (PB). O foco é identificado, neste estudo, como o constituinte que veicula a informação não-pressuposta na sentença, enquanto a pressuposição veicula a informação partilhada pelos interlocutores em uma situação discursiva. O fenômeno da focalização não está livre da marcação sintática. As estratégias de focalizar o sujeito não correspondem exatamente às estratégias de focalizar o objeto. Em relação à focalização do sujeito, nossa hipótese a é que o PB, por estar perdendo a propriedade de língua de sujeito nulo, emprega as estratégias de focalização das línguas de sujeito não-nulo, como o inglês e o francês. Quanto à focalização do objeto, parece não haver distinção no modo como os falantes das línguas em geral focalizam esse constituinte.
\end{abstract}

PALAVRAS-CHAVE: foco; sujeito; objeto; sintaxe; português brasileiro.

ABSTRACT: This paper is about subject and object focalization in SVO sentences in Brazilian Portuguese (henceforth BP). The focus is identified, in this study, as the constituent that conducts the non-presupposed information in the sentence, whereas the presupposition refers to information shared by the speakers in a discursive situation. The phenomenon of focalization is not free of the syntactic marking. The strategies to focalize the subject do not correspond exactly to the strategies used to focalize the object. Concerning the focalization in the subject, our hypothesis is that the BP, because it is 'losing' the properties of a null-subject language, makes use of the same focalization strategies of non-null languages such as English and French. As for the object focalization, there seems to be no distinction in the way the speakers focus such element.

KEYWORDS: focus; subject; object; sintax; Brazilian Portuguese.

RESUMEN: Este trabajo trata de la focalización del sujeto y del objeto en las sentencias SVO del portugués brasileño (PB). El foco es identificado, en este estudio, como el constituyente que transmite la información no-presupuesta en la sentencia, mientras que la presuposición transmite la información compartida por los interlocutores en una situación discursiva. El fenómeno de la focalización no está libre de la marcación sintáctica. Las estrategias de focalizar el sujeto no corresponden exactamente a las estrategias de focalizar el objeto. En relación a la focalización del sujeto, nuestra hipótesis es que el PB, por estar perdiendo la propiedad de lengua de sujeto nulo, emplea las estrategias de focalización de las lenguas de sujeto no-nulo, como el inglés y el francés. Cuanto a la focalización del objeto, parece no haber distinción en el modo como los hablantes de las lenguas en general focalizan ese constituyente.

PALABRAS-CLAVE: foco; sujeto; objeto; sintaxis; portugués brasileño.

\section{INTRODUÇÃO}

O mecanismo utilizado na focalização de constituintes muda de acordo com a sintaxe das línguas. Há línguas que permitem flexibilidade/variação da ordem de constituintes nas sentenças, como o italiano, o espanhol, o Português Europeu (PE), o grego. Há línguas que não apresentam essa possibilidade de variação da ordem dos constituintes, como o inglês e o francês.

Uma língua privilegia determinada estratégia de focalização em detrimento de outra que não acarreta qualquer violação gramatical. $\mathrm{O}$ italiano não recorre à estratégia de focalização do francês ou àquela do inglês, ainda que essas não violem nenhum princípio gramatical. O francês adota a estratégia clivada (reduzida), e não a estratégia de focalização in situ do inglês.

O PB é uma língua que não apresenta inversão livre do sujeito, mas não é considerada uma língua de sujeito nulo genuína. É classificada atualmente como uma língua pro-drop parcial; tanto que ainda apresenta resquícios de inversão (PILATI, 2006) e não apresenta efeitos that-t (MENUZZI, 2000), que são algumas das propriedades que caracterizam as línguas de sujeito nulo, como o italiano. O PB permite uma clivada 
sujeito em contexto pergunta-resposta, e não permite uma clivada objeto nesse mesmo contexto, como o francês. Mas permite que uma pseudoclivada, tanto sujeito quanto objeto, responda uma interrogativa-Wh. Isso é um reflexo da estrutura sintática diferente desses dois tipos de sentença. Quando se analisa paralelamente as estratégias de focalizar o sujeito e o objeto, verifica-se que uma proposta de análise unificada para as estratégias de focalização desses constituintes no PB não é satisfatória.

Este estudo parte da hipótese de que a focalização no PB não deve ser vista como um fenômeno estritamente prosódico. Os elementos focalizados aparecem destacados na sentença no PB de duas formas: (i) por meio da sintaxe; (ii) através de uma combinação entre prosódia e uma posição sintática específica de foco. O uso recorrente das construções clivadas (de todos os tipos), não só nos casos de foco contrastivo, é um forte indício de que os falantes do PB preferem destacar o constituinte focalizado, seja ele sujeito ou objeto, na sintaxe.

Neste artigo explora-se o modo como o sujeito e o objeto são focalizados nas sentenças Sujeito-VerboObjeto (SVO), um caso de focalização in situ, que é uma das estratégias de focalização empregada pelos falantes do PB (QUAREZEMIN, 2009). O presente texto inicia-se com uma identificação dos tipos de foco encontrados nas sentenças das línguas naturais; em seguida, apresenta-se a focalização in situ do sujeito junto com uma análise para os casos encontrados por Quarezemin (2009); por fim, é apresentada a focalização in situ do objeto também seguida de uma análise estrutural. Ressalta-se que a focalização do sujeito não corresponde exatamente à focalização do objeto; propõe-se uma análise diferenciada, nos moldes da abordagem cartográfica, para cada estratégia de focalização empregada pelos falantes do PB.

\section{DIFERENTES TIPOS DE FOCO NAS SENTENÇAS}

O foco é um recurso empregado pelo falante para fazer com que o ouvinte fique atento a uma parte do enunciado. Há dois tipos maiores de foco na literatura: o foco amplo e o foco estreito. O primeiro é visto frequentemente como um foco que não desencadeia uma relação operador-variável, enquanto o segundo desencadeia a relação operador-variável por meio de uma configuração de escopo. Com relação aos padrões de proeminência das línguas, o foco amplo normalmente recebe um acento não-marcado/neutro; já o foco estreito recebe um acento marcado.

O contexto desempenha um papel fundamental na identificação do foco de uma sentença, a não ser que a sintaxe dela explicite que houve uma operação de focalização, como o que acontece com as clivadas. A operação se processa de tal forma que a estrutura resultante tem uma posição destinada para o constituinte focalizado. De fato, aplicado o processo de clivagem à sentença (1) obtém-se (2):

(1) O Pedro parou de cantar.

(2) a. Foi o Pedro que parou de cantar.

b. Foi de cantar que o Pedro parou.

c. ?Foi parar de cantar que o Pedro fez.

O foco em cada uma das sentenças em (2) é o constituinte situado entre a cópula foi e o complementizador que. Isto pode ser assegurado sem que precisemos recorrer a contextos previamente estabelecidos.

Entretanto, se não é construída na sintaxe uma estrutura que indique qual é o foco, é preciso recorrer ao contexto para identificar o constituinte focalizado. É o que faz Zubizarreta (1998). Tendo em vista dois tipos de foco e o traço semântico [contraste], a autora fixa uma interrogativa-Wh como um contexto para o foco não-contrastivo, entendido como a informação que a pergunta solicita (cf. exemplo 3); e uma afirmação prévia como um contexto apropriado para o foco contrastivo, entendido como uma correção da afirmação prévia (cf. exemplo 5).

(3) a. O que a Maria comprou?

b. A Maria comprou [F um carro]. 
O constituinte um carro, que responde a pergunta (3a) substituindo a expressão-Wh, é o foco da sentença (3b). A pergunta, além de estabelecer o foco da sentença, pois solicita ao ouvinte que ele forneça uma informação desconhecida por parte do falante, também determina qual é a pressuposição. Substituindo a expressão-Wh da pergunta por um indefinido, como em (4), tem-se a pressuposição:

(4) A Maria comprou alguma coisa.

O foco contrastivo é identificado em um contexto como (5):

(5) a. A Maria comprou uma casa.

b. A Maria comprou UM CARRO (não uma casa).

O constituinte focalizado em (5b), além de veicular a informação que funciona como uma correção, apresenta um contraste em relação a outro constituinte, a expressão entre parênteses. Esse foco nega o valor da variável da afirmação contextual, para, em seguida, atribuir um novo valor a ela. Assim, em (5b) o falante nega o valor estabelecido para a variável x (uma casa) e introduz um novo valor para ela (um carro).

Kiss (1998) considera o traço [exaustivo] um traço semântico relevante para distinguir dois tipos de foco. $\mathrm{O}$ constituinte focalizado que é marcado pelo valor positivo do traço [exaustivo] deve ser lido como [xe apenas $x]$. Veja o que ocorre em (6):

(6) Foi UM PRÊMIO que a Ana ganhou.

Verifica-se que essa sentença apresenta um foco deslocado da posição de objeto (um prêmio), indicando identificação exaustiva: dentre um conjunto de presentes que a Ana poderia ter ganhado foi somente um prêmio que ela ganhou. Assim, o único valor para a variável x é um prêmio. Este é justamente o papel semântico-comunicativo do foco de identificação apontado pela autora ${ }^{1}$.

\section{SUJEITO FOCALIZADO IN SITU}

Uma das estratégias de focalizar o sujeito no PB é o uso da sentença simples SVO. Diferentemente do italiano, do espanhol e do PE, não há nenhuma alteração na ordem linear dos constituintes na sentença. No caso da focalização in situ do sujeito, a ordem SV é combinada com uma prosódia especial que destaca o sujeito, como ocorre em inglês.

De acordo com as propriedades sintáticas do PB, tem-se uma língua que não apresenta inversão livre, a estrutura VS do tipo do italiano, como uma estratégia de focalizar o sujeito; ainda que apresente sujeito nulo em certos contextos, aparente violação aos efeitos that-t, resquícios de inversão (locativa ou do tipo Choveu $a$ noite toda). Esse estado de coisas corrobora com a proposta de Belletti, Bennati, Sorace (2007), que dissocia a ocorrência de inversão livre (VS) do parâmetro pro-drop. Os resultados das autoras mostram que os falantes de uma língua de não sujeito nulo L1, como o inglês, quando expostos ao italiano como L2, fazem uso de sujeito nulo, redefinem o valor do parâmetro pro-drop, mas não empregam sentenças VS em contexto de focalização do sujeito. Para as autoras, a inversão livre constitui uma estratégia de focalizar o sujeito disponível apenas nas línguas que acessam diretamente uma posição baixa específica de foco. Os falantes do PB ainda empregam o sujeito nulo em certos contextos, mas a inversão livre não ocorre; o que mostra que a posição FocP acima de VP não está disponível para o sujeito focalizado nessa língua.

A focalização in situ do sujeito não é somente uma consequência da prosódia especial que incide sobre ele. Propõe-se que a forma fonológica $(\mathrm{PF})$ recebe a estrutura do componente sintático, identifica que o sujeito pré-verbal está em uma posição dedicada a sua propriedade discursiva e depois atribui a ele um acento especial. Aparentemente, uma sentença SVO neutra tem a mesma numeração de uma sentença SVO com

\footnotetext{
${ }^{1}$ Kiss (1998, p. 245) atribui ao foco de identificação o seguinte papel semântico-comunicativo em uma sentença: “um foco de identificação representa um subconjunto do conjunto de elementos dados contextualmente ou situacionalmente, para os quais o predicado pode se aplicar; é identificado como o subconjunto exaustivo deste conjunto para o qual o predicado realmente se aplica”.

${ }^{2}$ Neste estudo, entende-se por in situ todo processo de focalização que não acarreta alteração na ordem dos constituintes. Esses, por sua vez, ocupam uma posição específica de foco, mas, ainda assim, é mantida a ordem básica da sentença no PB: SVO.
} 
sujeito focalizado. Uma sentença como (7) pode ser empregada em dois contextos distintos, como se verifica em ( $\left.7^{\prime}\right)$.

$$
\begin{aligned}
& \text { (7) O Pedro chegou às } 3 \text { horas. } \\
& \text { (7')a. Quando o Pedro chegou? } \\
& \text { b. Quem chegou às } 3 \text { horas? }
\end{aligned}
$$

Quando se emprega (7) em resposta a (7’a), o sujeito O Pedro faz parte da pergunta, e o foco é o adjunto às 3 horas. Nenhum acento especial é atribuído ao sujeito. No caso em que (7) responde (7’b), o sujeito $O$ Pedro é o foco de informação da sentença e está em uma posição sintática específica. Um acento especial aparece sobre ele, acarretando uma prosódia particular.

Uma mesma sequência de constituintes pode ser usada com uma marcação prosódica diferente. Para que a sentença (7) seja interpretada corretamente pelos sistemas de interface PF e LF (forma lógica), tanto no caso de (7’a) quanto no caso de (7’b), é necessário que a sintaxe envie alguma pista; uma vez assumido o modelo-T tradicional, no qual os componentes PF e LF não interagem entre si. Se a focalização in situ do sujeito fosse estritamente prosódica, como LF interpretaria corretamente aquele constituinte? A ativação de uma posição específica de foco na estrutura, FocP dentro de DP (ABOH, 2004), sinaliza para PF e LF que o sujeito que está ali é o foco da sentença. É defendido aqui que a focalização in situ do sujeito é um processo sintático e prosódico. Não se segue uma análise na qual a sintaxe gera outputs, e os filtros nas interfaces PF e LF devem escolher o output que satisfaz seus requisitos (COSTA; FIGUEIREDO SILVA, 2006).

Nesta proposta, não há duas abordagens independentes: sintaxe de um lado, e fonologia do outro. Há um sistema único que trabalha conjuntamente sintaxe-prosódia (BOCCI, 2006). A computação parte do léxico (numeração) em direção à sintaxe, que aplica as operações necessárias para estruturar a sentença. Depois a sintaxe envia a representação para PF, que aplica as regras intrínsecas ao seu componente. Não cabe aqui um modelo de análise no qual a sintaxe envia uma representação para o componente fonológico, que aplica as regras prosódicas, depois a representação volta para a sintaxe, que coloca os constituintes nas suas devidas posições, e, por fim, vai até LF.

O recurso da posição sintática específica de foco junto com uma prosódia especial no sujeito é empregado pelas línguas que não permitem o reordenamento de constituintes, como o inglês (BELLETTI, 2008; $\mathrm{ABOH}, 2004)$. Uma língua como o italiano não precisa recorrer à marcação prosódica, a posição sintática é suficiente para destacar o foco da sentença.

(8) a. Piero è arrivato alle $3^{3}$.

(Quando è arrivato Piero?)

b. (Alle 3) è arrivato Piero (alle 3).

(Chi è arrivato alle 3?)

O sujeito foco de informação sempre aparece em posição pós-verbal em italiano, como em (8b), ele ocupa uma posição baixa de foco. Nenhum acento especial aparece sobre ele. Se o sujeito está em posição préverbal, como em (8a), deve estar topicalizado. O único caso de sujeito pré-verbal focalizado em italiano é com interpretação contrastiva.

$\mathrm{O}$ sujeito $\mathrm{FI}^{4}$ no $\mathrm{PB}$ não ocupa uma posição foco tão baixa quanto à posição foco do italiano, mas também não está em uma posição fora do domínio sentencial. Fernandes (2007) propõe que o sujeito FI ocupa o

\footnotetext{
${ }^{3}$ Tradução: a. Pedro chegou às 3.

(Quando Pedro chegou?)

b. (Às 3) Pedro chegou (às 3).

(Quem chegou às 3?)

${ }^{4}$ Emprega-se, nesse estudo, a abreviação FI para o foco de informação e FC para o foco contrastivo.
} 
especificador de CP no PB. Se essa é a posição ocupada por um sujeito FI, então também deve valer para o objeto FI. No PB, o objeto no domínio $\mathrm{CP}$ não pode estar associado apenas à informação nova. Necessariamente, envolve contraste/correção, tanto que não podemos responder uma interrogativa-Wh com uma sentença OSV. Nas línguas em que o sujeito FI ocupa uma posição no domínio CP, siciliano (9) e húngaro $(10)^{5}$, por exemplo, o objeto FI também pode figurar nessa posição sem envolver contraste/correção, como nos exemplos em (b).

(9) a. Montalbano sono. (Chi è?)

(Montalbano sou)

b. N'articulu scrissi. (Chi scrivisti airi?)

(Um artigo escrevi)

(10) a. Hans telefonált. (Who called?)

(Hans telefonou)

b. Mari egy pulóvert vett. (Mit vett Mari?)

(Maria um suéter comprou)

Nos exemplos em (9) e (10), tanto a sentença com a ordem SV quanto a sentença com a ordem OV podem ser empregadas em contextos de pergunta-resposta. No $\mathrm{PB}$, as sentenças com objeto deslocado não respondem uma interrogativa-Wh. Isso é confirmado no experimento acerca das estratégias de focalização informacional do objeto aplicado por Quarezemin $(2009)^{6}$. Nenhum falante selecionou a sentença com deslocamento explícito do objeto como opção de focalização informacional desse constituinte.

Também não parece válido o argumento de Fernandes (2007) de que o sujeito FI ocupa a mesma posição da expressão-Wh porque ele é o elemento que a substitui na resposta. É certo que um elemento-Wh e um foco não podem coocorrer na sentença porque disputam pela mesma posição, mas apenas a expressão-Wh e o foco contrastivo devem sempre estar no domínio $\mathrm{CP}$.

(11) Quem comprou o carro?

b. [F O Pedro] comprou o carro.

(12) a. O que o Pedro comprou?

b. \#[F O carro $]$ o Pedro comprou ${ }^{7}$.

Em (11b), não há deslocamento do sujeito focalizado para a periferia esquerda, por isso a sentença pode ser empregada nesse contexto. Já em (12b), o deslocamento do objeto focalizado é explícito, e a sentença não é adequada ao contexto. Se o argumento de Fernandes, de que o foco deve ocupar a mesma posição da expressão-Wh, é válido para o sujeito, então deveria ser válido também para o objeto; uma vez que ele é o constituinte que substitui a expressão-Wh na resposta. Entretanto, verifica-se através do contraste entre as sentenças em (11) e (12) que isso não é possível.

Quanto à distribuição de advérbios e o sujeito FI, observa-se que um advérbio alto não pode ocorrer entre o sujeito e o verbo quando a sentença é empregada em um contexto pergunta-resposta.

a. Quem recebeu o prêmio elegantemente?

\footnotetext{
${ }^{5}$ Exemplos extraídos de Cruschina (2004) e Belletti (2008), respectivamente.

${ }^{6}$ A autora elaborou um questionário do tipo múltipla escolha com contextos discursivos que finalizavam com uma pergunta. Esta tinha nas alternativas de respostas maneiras diferentes de focalizar o objeto FI. O participante assinalava aquela que ele considerava a resposta mais natural em cada contex to dado.

${ }^{7}$ O sinal \# indica que a sentença é gramatical, mas não aceitável naquele contexto.
} 
a'. ?Quem elegantemente recebeu o prêmio?

b. \#O Mauro elegantemente recebeu o prêmio.

c. Elegantemente o Mauro recebeu o prêmio.

d. O Mauro recebeu o prêmio elegantemente.

A sentença (13b) pode ser usada em um contexto de contraste/correção, do tipo: O MAURO frequentemente joga futebol, não o Luca. A mesma situação não se verifica se entre o sujeito e o verbo houver um advérbio baixo, como em (14).

(14) a. Quem quase beijou a Maria?

b. O Pedro quase beijou a Maria.

Nesse caso, o advérbio figura em uma posição baixa, diferentemente do advérbio alto. Dessa forma, não implica que o sujeito deva ocupar uma posição na periferia esquerda da sentença. Ainda, segundo Rizzi (c.p), empregar a posição do advérbio como teste para identificar a posição do sujeito na estrutura é muito complicado. É difícil precisar a posição do advérbio na estrutura, ele pode estar entre CP e IP, e, ainda assim, não quer dizer que o sujeito esteja na periferia da sentença.

Fernandes (2007) aponta casos em que o advérbio tem leitura orientada para o sujeito, como em (15), e figura entre o sujeito e o verbo na sentença. A autora afirma que essa intervenção é possível porque o sujeito está em uma posição no domínio CP.

(15) a. Quem inteligentemente leu o livro?

b. A Maria inteligentemente leu o livro.

De acordo com a análise de Rizzi e Shlonsky (2007), a posição do advérbio nesse caso não é na periferia esquerda da sentença. Os autores afirmam que há um subcampo entre o domínio CP e o domínio IP que tem dois núcleos, Subj e Mod. O primeiro atrai o sujeito, e o segundo atrai advérbios altos. A ordem entre os dois é livre, ou seja, sujeito-advérbio ou advérbio-sujeito ${ }^{8}$. Dessa forma, a presença do advérbio entre o sujeito e o verbo na sentença (15a) não indica que o sujeito está no campo CP. Tanto o sujeito quanto o advérbio podem estar em uma posição no subcampo entre CP e IP. Os autores ainda observam que, nos casos em que o CP está truncado, não há ativação de posição tópico e foco na periferia esquerda da sentença. Rizzi e Shlonsky (2007) afirmam que isso só é possível porque o advérbio preposto faz parte do domínio IP, compatível com um sistema Comp truncado.

A análise proposta neste estudo é a de que nas sentenças SV no PB o sujeito FI não está em uma posição alta, no domínio CP; nem na posição em que checa Caso nominativo, no domínio TP. O DP sujeito vai para o especificador de SubjP para satisfazer o critério sujeito (RIZZI, 2004). Ainda propõe-se, seguindo Aboh (2004; 2007), que o NP vai para o especificador de FocP dentro de DP.

(16) a. Quem comprou o carro?

b. [F A Maria] comprou um carro.

c. $[$ SubjP DP A $[$ FocP Mariai $[$ Foc $+\mathrm{F}[\operatorname{Subj}[\mathrm{TP}[\mathrm{T}$ comprouj $[\mathrm{vP}$ ti $[\mathrm{v}[\mathrm{VP}[\mathrm{v}$ t um carro $]]]]]]]]]]]$

\footnotetext{
${ }^{8}$ Rizzi e Shlonsky (2007, p. 24) apresentam a seguinte representação para a ordenação livre entre sujeito e advérbio:

a. Subj $[$ AdvP Mod $[$ Agr .....

b. AdvP Mod [Subj [Agr .....
} 


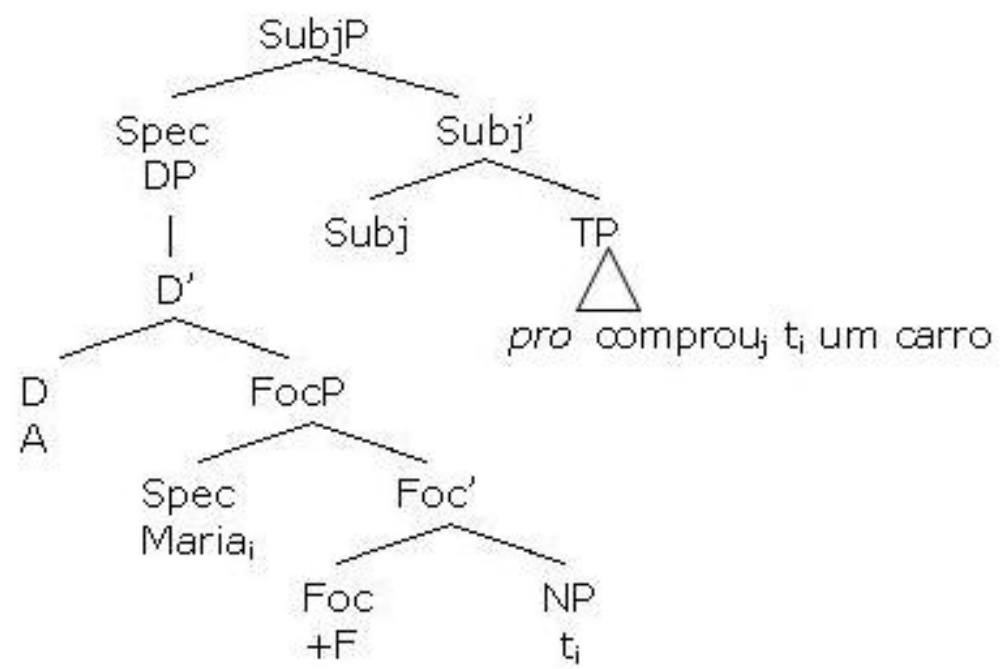

O sujeito não está relacionado a nenhum traço de contraste/correção que desencadeie um deslocamento para a periferia esquerda. Este possui um critério inerente a sua propriedade de sujeito que deve ser satisfeito. Por isso, o DP a Maria vai para o especificador de SubjP, entrando em relação direta com o núcleo Subj. O NP sujeito Maria checa o traço [+F] do núcleo Foc, pois ocupa o especificador de FocP. Segundo Rizzi e Shlonsky (2007), o traço EPP é convertido em critério sujeito na abordagem cartográfica/criterial, pois o constituinte que checa esse traço está sujeito ao congelamento criterial. A posição criterial de sujeito (SubjP) é dissociada da posição de checagem de Caso nominativo (TP). Assim, é possível que o sujeito focalizado satisfaça dois critérios discursivos ${ }^{9}$ em uma posição criterial. Se permanecesse em Spec TP, ainda que tivesse FocP projetado em DP, o sujeito focalizado checaria uma propriedade gramatical (Caso) e uma propriedade discursiva (Foco) na mesma posição, e que não é uma posição criterial.

Com uma análise desse tipo, é possível satisfazer tanto o critério foco quanto o critério sujeito, sem violar o congelamento criterial. Não há nenhum problema com o fato de um mesmo constituinte satisfazer dois critérios concomitantemente. Rizzi (c.p) aponta que há alguns casos em italiano em que essa situação se verifica, como na interrogativa indireta, em (17).

(17) Gianni non sapeva [quale LIBRO] avessero raccomandato di leggere, non quale articolo.

(João não sabia qual livro tinha recomendado para ler, não qual artigo)

Todo o sintagma quale libro satisfaz o critério foco e, dentro desse bloco, a expressão quale satisfaz o critério Q. A expressão quale libro não pode sofrer movimento para a posição inicial porque viola o congelamento criterial.

(18)

*Quale LIBRO Gianni non sapeva [ [avessero raccomandato di leggere, non quale

articolo.

Assume-se que o sujeito sai diretamente da posição criterial (Spec VP), não passando por Spec TP (MENUZZI, 2000). Não há nenhum problema com a checagem de Caso nominativo, pois esta é feita por meio de Agree. Chomsky (2001) afirma que Caso não desencadeia movimento porque há a relação sondaalvo entre dois elementos de uma cadeia que elimina do sistema o traço não-interpretável de Caso através de Agree. O desencadeador do movimento de constituintes é um traço-phi, como EPP.

A posição FocP interna a DP nos casos de sujeito FI nas sentenças SV do PB não é uma posição default, como é FocP acima de VP e FocP no domínio CP, mas é necessária, visto que o PB emprega a sentença SV como estratégia de focalizar o sujeito, e que as interfaces PF e LF interpretam a sentença da configuração sintática. O PB não é uma língua que acessa a posição baixa de foco nos casos de sujeito FI, como o italiano. $\mathrm{O}$ PB emprega essa posição de uma forma diferenciada, recorrendo ao uso da sentença clivada, como o francês.

${ }^{9}$ Os critérios em questão são o critério sujeito e o critério foco. 
O sujeito também é focalizado contrastivamente em posição pré-verbal, uma estratégia de focalização in situ. Nesse caso, assim como ocorre com o sujeito FI, há uma prosódia especial sobre ele que o destaca na sentença, e o diferencia de uma sentença SVO neutra, sem sujeito focalizado.

Uma questão que se coloca é se a prosódia sobre o sujeito FI é a mesma que aparece sobre o sujeito FC, e se os dois ocupam a mesma posição sintática na estrutura. O sujeito FI aparece em contextos de perguntaresposta, enquanto o sujeito FC aparece em contextos de contraste/correção. Assim, verifica-se que, do ponto de vista semântico, há uma diferença entre os dois focos e que essa diferença deve ser identificada pelo componente LF para que eles sejam corretamente interpretados.

De acordo com Belletti (2009), há uma diferença prosódica entre a sentença SV com sujeito FI e a sentença SV com sujeito FC em inglês. Ainda que essa diferença seja sutil, é captada pelos falantes nativos dessa língua. Segundo a autora, a focalização contrastiva do sujeito em italiano pode ser comparada à focalização prosódica do inglês. Nos dois casos, o sujeito está na posição pré-verbal, sem alteração na ordem de constituintes; ocupa uma posição sintática própria de foco e é marcado por uma prosódia especial que sinaliza ao interlocutor que o falante está corrigindo uma informação prévia. Isso também vale para o PB.

Bocci (2008) mostra que o contorno prosódico de uma sentença SVO com sujeito FC é o mesmo de uma sentença OSV com objeto FC em italiano. O contorno entoacional de uma sentença SVO com sujeito FC no PB é equivalente ao contorno entoacional da sentença com deslocamento do objeto para a posição inicial. Tanto que uma sentença OSV não pode ser empregada em um contexto out-of-the-blue ${ }^{10}$.
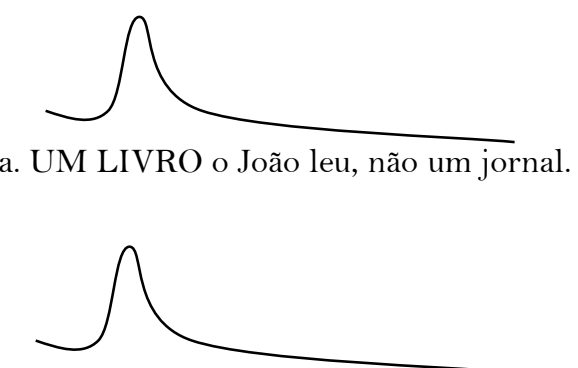

b. O JOÃO leu um livro, não o Pedro.

O PB é uma língua de núcleo inicial (VO), o deslocamento explícito do objeto em (19a) aponta que ele não está mais no domínio TP. Esse deslocamento só é possível porque o objeto tem um traço criterial que deve ser checado em uma posição sintática específica. Essa posição é o especificador de FocP no domínio CP. Pelo fato de o foco contrastivo ocupar essa posição é que ele recebe um acento especial, tornando-o distinto de um foco de informação nos componentes PF e LF. Um simples foco de informação não pode ocupar uma posição no domínio $\mathrm{CP}$ no $\mathrm{PB}$, mesmo que apareça em posição inicial, como mostramos na seção anterior.

É possível estender essa análise para os casos de focalização contrastiva do sujeito, como em (19b). Ainda que ele apareça na sua posição superficial, o sujeito $\mathrm{FC}$ ocupa uma posição no domínio $\mathrm{CP}$, tanto que um elemento topicalizado pode aparecer entre ele e o verbo, como em (20).

(20) O JOÃO ontem leu um livro, não o Pedro.

Se a sentença (20) respondesse uma pergunta-Wh, como Quem ontem leu um livro?, o advérbio ontem não poderia figurar entre o sujeito e o verbo. Se assim fosse, ela seria inadequada ao contexto de pergunta-Wh.

Os resultados do experimento aplicado por Quarezemin (2009) sobre a focalização contrastiva do sujeito mostram que os falantes do PB preferem empregar a sentença clivada como estratégia de focalização. As sentenças SVO apareceram apenas em $20 \%$ dos dados como estratégia de focalização contrastiva do sujeito.

Para todos esses casos, propõe-se que o sujeito sai do domínio TP, salta SubjP, que é uma posição criterial, e ocupa o especificador de FocP no domínio CP. Um pro expletivo checa o traço EPP, satisfazendo o critério sujeito (RIZZI; SHLONSKY 2007; RIZZI, 2006). Abaixo está a derivação proposta para a estratégia SVO com sujeito FC.

${ }^{10}$ Esta expressão é usada para indicar contex to neutro. 
O ENÉIAS perdeu as eleições (não o FHC).

\section{$\left[\right.$ FocP O ENÉIAS $\mathrm{E}_{\mathrm{i}}\left[\mathrm{Foc}+\mathrm{F}\left[\mathrm{Subjp}\right.\right.$ pro $\left[\mathrm{TP}\left[\mathrm{T}_{\text {perdeu }}\left[\mathrm{vvP}_{\mathrm{i}}\left[\mathrm{v}\left[\mathrm{vP}\left[\mathrm{v} \mathrm{t}_{\mathrm{j}}[\right.\right.\right.\right.\right.\right.$ as eleições $\left.\left.\left.\left.\left.\left.\left.\left.\left.]\right]\right]\right]\right]\right]\right]\right]\right]\right]$}

O critério Foco é satisfeito na configuração default especificador-núcleo. Foc é marcado pelo traço [+F] que parte da numeração, não ocasionando nenhuma violação da condição de inclusividade. O movimento do sujeito FC para FocP na periferia esquerda não fere a condição de Last Resort (CHOMSKY, 1995), porque tem um efeito de escopo-discursivo nas interfaces associado ao especificador de FocP. Se o sujeito FC for movido para SubjP, como ocorre com o sujeito FI, não poderá mais sair dessa posição devido ao congelamento criterial. Assim, não alcança a posição na periferia esquerda da sentença compatível com a sua interpretação focal.

\section{OBJETO FOCALIZADO IN SITU}

O objeto FI sempre aparece na sua posição de base no PB. A estratégia de focalização empregada pelos falantes é a sentença SVO (QUAREZEMIN, 2009). Nenhum caso de clivada canônica foi constatado, diferentemente do que ocorre com o sujeito FI. Mais uma vez observa-se que a assimetria sujeito-objeto se reflete no fenômeno da focalização. Não há nenhum critério objeto a ser satisfeito, como o critério sujeito que marca a relação de aboutness da sentença.

As línguas naturais não apresentam grandes diferenças entre si no que se refere à focalização do objeto. Os falantes do PB, assim como os falantes do italiano, espanhol, PE, inglês e francês, deixam o objeto focalizado informacionalmente na posição mais encaixada da sentença. Nessa posição não ocorre nenhum conflito interpretativo entre sintaxe e PF.

Nos casos em que a sentença SVO é empregada para focalizar informacionalmente o objeto, a posição FocP acima de VP é ativada. Nada impede que o objeto ocupe o especificador dessa posição, checando o traço $[+\mathrm{F}]$ contra o núcleo Foc.

(22) a. O que a Ana comprou?

b. A Ana comprou [F uma bolsa].

c. $\left[\right.$ SubjP A Ana $\left[\mathrm{TP}\left[\mathrm{T}\right.\right.$ comprou $\left[\mathrm{FocP}\right.$ uma bolsa $\left.\left.\left.\left.{ }_{k}\left[\mathrm{Foc}+\mathrm{F}\left[\mathrm{VP}\left[\mathrm{V} \mathrm{t}_{\mathrm{j}} \mathrm{t}_{\mathrm{k}}\right]\right]\right]\right]\right]\right]\right]$

Em (22c), o objeto deixa a sua posição temática para satisfazer o critério foco através da concordância especificador-núcleo. Ainda que um elemento esteja posicionado entre o verbo e o objeto, como em (23b), o foco alcança sem problemas o especificador de FocP.

(23) a. O que o Pedro comeu ontem?

b. O Pedro comeu ontem [F um doce].

c. O Pedro comeu [F um doce] ontem.

Posições de tópico também podem ser ativadas na periferia de VP. No caso de (23b), o advérbio ontem aparece no especificador de TopP, logo acima de FocP, como verifica-se na representação em (24).

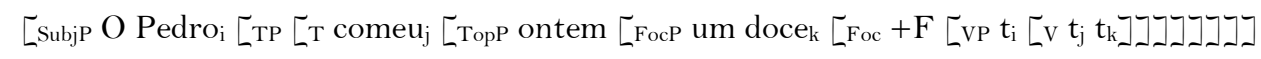

A estratégia de focalização in situ do objeto FI não é combinada com nenhum recurso prosódico especial, como ocorre com a focalização in situ do sujeito FI. Também observamos que um rearranjo de elementos na sentença não é possível quando o sujeito é foco, mas é possível que ocorra um reordenamento dos constituintes que estão depois do verbo. Em uma sentença com objeto direto (OD) e com objeto indireto (OI), a ordem entre os dois pode ser modificada a depender de qual deles é o foco na sentença.

$$
\text { a. Para quem a Joana deu o livro? }
$$

a'. A Joana deu o livro para [F a Marta]. 


\section{b. O que a Joana deu para a Marta? \\ b'. A Joana deu para a Marta [F o livro].}

A possibilidade de reordenamento entre os constituintes que aparecem depois do verbo é mais um indício da assimetria sujeito-objeto no PB. De acordo com Costa e Figueiredo Silva (2006), o comportamento dos complementos de verbos bi-transitivos mostra que o PB codifica o foco na sintaxe. Caso contrário, o rearranjo entre OD e OI não seria possível. Para os autores, o fato de o sujeito FI não aparecer depois do verbo nessa língua não indica que o foco não seja codificado na sintaxe. A inversão livre não é uma estratégia de focalização escolhida pelos falantes do PB, porque essa língua, diferentemente do italiano, não permite a ativação da posição foco acima de VP para os casos de focalização do sujeito.

A sentença SVO pode ser empregada em contexto de focalização contrastiva no PB sem violar nenhum princípio gramatical. Contudo, os falantes preferem destacar o objeto foco contrastivo sintaticamente, recorrendo à sentença clivada (QUAREZEMIN, 2009).

Para os casos em que o objeto FC está in situ, tem-se três possibilidades de análise: (i) objeto permanecendo na sua posição temática; (ii) objeto em Spec FocP baixo e relação de Agree com o domínio CP e (iii) objeto em Spec FocP alto e remnant movement de TP (movimento proposto por Kayne (1994)).

A primeira possibilidade é descartada, visto que se assume a abordagem cartográfica, que reserva uma posição específica para o constituinte que apresenta uma propriedade discursiva particular, como foco. A segunda análise envolve uma posição sintática específica para o foco, mas não é tão restritiva, já que permite que um elemento que não é um simples foco de informação esteja nessa posição. Se um foco contrastivo também pode ocupar Spec FocP acima de vP, o componente LF dificilmente diferenciará um FI de um FC. Ainda que se assuma a relação Agree entre uma posição no domínio CP e a posição baixa de foco, acarretando leitura de contraste, não estaremos respeitando a relação entre a posição sintática foco e o tipo de foco (RIZZI 2004; BELLETTI, 2004). A terceira análise se mostra como a mais apropriada de acordo com a abordagem cartográfica assumida neste estudo. Essa análise é proposta por Belletti (2004) para as sentenças do italiano com objeto $\mathrm{FC}$ in situ e pode ser estendida às sentenças SVO do PB com objeto FC. Assumindo essa proposta, é possível manter a hipótese restritiva entre posição sintática e tipo de foco. A função discursiva do objeto FC é marcada na sintaxe.

a. A Marta ganha UMA FLOR (todos os dias), não um chocolate.

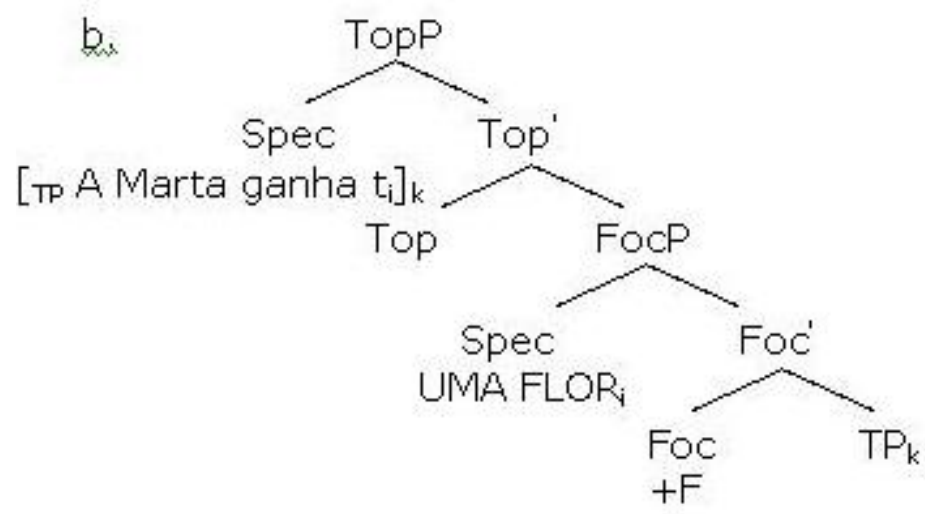

O movimento do objeto FC para o especificador de FocP ocorre na sintaxe visível, não espera até LF. O critério foco é satisfeito na sintaxe. Essa representação não fere nenhum princípio de economia, uma vez que o remnant movement de TP também é justificado por razões discursivas.

\section{CONSIDERAÇÕES FINAIS}

O foco foi identificado, neste estudo, como o constituinte que veicula a informação não-pressuposta na sentença, enquanto a pressuposição veicula a informação partilhada pelos interlocutores em uma situação discursiva. Foram verificadas as propriedades envolvidas na focalização do sujeito e do objeto em sentenças SVO do português brasileiro. A partir de tais propriedades, observou-se que a focalização do sujeito não 
corresponde à focalização do objeto. A assimetria sujeito-objeto também é mantida nos casos de focalização desses constituintes.

Em relação à focalização do sujeito, foi visto que a mesma não é somente uma consequência da prosódia especial que incide sobre o sujeito. Neste artigo, foi defendido que esse tipo de focalização envolve um processo sintático e prosódico. O recurso da posição sintática específica de foco junto com uma prosódia especial no sujeito é empregado pelas línguas que não permitem o reordenamento de constituintes, como o inglês (BELLETTI, 2008; ABOH, 2004). O sujeito FI no PB não ocupa uma posição foco tão baixa quanto à posição foco do italiano, mas também não está em uma posição fora do domínio sentencial. Já o sujeito FC figura em uma posição alta, na periferia esquerda da sentença SVO.

Quanto à focalização do objeto, observou-se que, pelo fato de o objeto figurar na posição final da sentença e não ter nenhum critério a satisfazer, como no caso do sujeito, as línguas em geral se comportam da mesma maneira no que tange à focalização em sentenças SVO. O objeto FI ocupa uma posição foco baixa (FocP acima de VP), enquanto o objeto FC ocupa a posição foco na periferia esquerda da sentença.

A abordagem cartográfica dá conta da assimetria sujeito-objeto focalizados tratada neste estudo. Cada tipo de foco está associado a uma posição estrutural específica. Dessa forma, os componentes de interface fonológica e semântica conseguem interpretar a sentença da configuração sintática, por meio de um processo transparente.

\section{REFERÊNCIAS}

ABOH, Enoch. Topic and focus within D. Linguistics in the Netherlands, n. 21, p. 1-12, 2004.

. Information structuring begins with the numeration. Trabalho apresentado na MPI conference on Information Structure in Adult and Child Language, Nijmegen, at the Syntax Circle, Meertens Institute, and at the Syntax seminar, University of Groningen, 2007.

BELLETTI, Adriana. Aspects of the low IP area. In: RIZZI, Luigi (Ed.). The cartography of syntactic structures, v. 2: The structure of CP and, New York: Oxford University Press, 2004. p. 16-51.

. Answering strategies: new information subjects and the nature of clefts. In: BELLETTI, Adriana (Org.). Structure and Strategies. London: Routledge, 2008.

. Anotações do curso Acquisizione Del Linguaggio L2 realizado na Università di Siena, 2009.

BELLETTI, Adriana; BENNATI, Elisa; SORACE, A. Theoretical and developmental issues in the syntax of subjects: evidence from near-native Italian. Natural language and linguistic theory, v. 25, n. 4, p. 657-689, 2007.

BOCCI, Giuliano. Criterial positions and left periphery in Italian: evidence for the syntactic encoding of contrastive focus. Nanzan linguistics, special issue, 2006.

On the Syntax-Prosody Interface: an analysis of the prosodic properties of postfocal material in $\overline{\text { Italian }}$ and its implications. Nanzan Linguistics, n. 5: special issue, p.13-42, 2008.

CHOMSKY, Noam. The minimalist program. Cambridge, Mass.: MIT Press, 1995. Press, 2001.

Derivation by phase. In: KENSTOWICZ, M. (Ed.). Ken Hale: a life in language. Cambridge: MIT

COSTA, João; FIGUEIREDO SILVA, Maria Cristina. On the (in)dependence relations between syntax and pragmatics. In: MOLNÁR, V; WINKLER, S. (Eds.). The Architecture of Focus. Berlin: Mouton de Gruyter, 2006. p. 83-104.

CRUSCHINA, Silvio. Il Focus di nuova informazione e la periferia sinistra: la struttura informative della frase in Siciliano. 2004. 21 f. Dissertação (Mestrado em Linguística) - Ciscl, Università di Siena, Siena, 2004.

FERNANDES, Flaviane. Ordem, focalização e preenchimento em português: sintaxe e prosódia. 2007. 444f. Tese (Doutorado em Linguística) - Instituto de Estudos da Linguagem, Universidade Estadual de Campinas, Campinas, 2007.

KAYNE, Richard. The antisymmetry of syntax. Cambridge: MIT Press, 1994. 
KISS, Katalin È. Focus identificational versus information focus. Language, v. 74, n. 2, . p. 245-273, 1998.

MENUZZI, Sérgio. That-trace effects in Portuguese. Fórum Linguístico, v. 2, n. 2: org. por Carlos Mioto, Heronides M. de Melo Moura E Roberta Pires de Oliveira, p.13-39, 2000.

PILATI, Eloisa. Aspectos sintáticos e semânticos das orações com ordem verbo-sujeito no português do Brasil. 2006. 253f. Tese (Doutorado em Linguística) - Programa de Pós-Graduação em Linguística, Universidade de Brasília, Brasília, 2006.

QUAREZEMIN, Sandra. Estratégias de focalização em português brasileiro - uma abordagem cartográfica. 2009. 289f. Tese (Doutorado em Linguística) - Programa de Pós-Graduação em Linguística, UFSC, Florianópolis, 2009.

RIZZI, Luigi. The fine structures of left periphery. In: HAEGEMAN, Liliane (Org.). Elements of grammar. Dordrecht: Klumer Academic Publishers, 1997. p. 281-337.

Locality and Left Periphery. In: BELLETTI, Adriana (Org.). Structure and beyond. The cartography of sybtactic structures. New York: Oxford University Press, 2004. v. 3: p. 223-251.

. On the form of chains: criterial positions and ECP effects. In: CHENG, S.; CORVER, N. (Eds.). Wh-movement: Moving on. Cambridge: MIT Press, 2006. p. 97-34.

RIZZI, Luigi; SHLONSKY, Ur. Strategies of subject extraction. In: SAUERLAND, Uli; GÄRTNER, HanMartin. Inferces + recursion = language? Berlin: Mouton de Gruyter 2007.

ZUBIZARRETA, Maria Luiza. Prosody, focus and word order. Cambridge: MIT Press, 1998.

Recebido em 30/11/12. Aprovado em 16/12/12. 